\title{
Development of scanning electrochemical microscopy (SECM) techniques for the optimization of dye sensitized solar cells
}

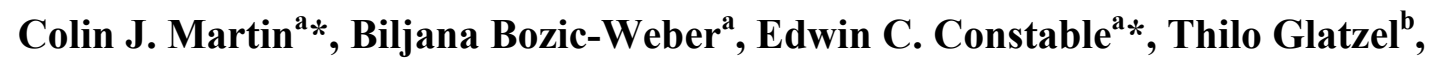 \\ Catherine E. Housecroft ${ }^{\mathrm{a}}$ and Iain A. Wright ${ }^{\mathrm{a}}$
}

${ }^{a}$ Department of Chemistry, University of Basel, Spitalstrasse 51, CH-4056 Basel, Switzerland. Fax:+41 61267 1018; Tel: +41612671001; E-mail:edwin.constable@unibas.ch

${ }^{b}$ Department of Physics, University of Basel, Klingelbergstrasse 82, CH-4056 Basel, Switzerland

\begin{abstract}
Methods for high-throughput validation of cell components for use in dye sensitized solar cells (DSCs) are needed as the global production of such cells becomes widespread. We have carried out preliminary investigations into the use of scanning electrochemical microscopy (SECM) for high-throughput screening of materials. By coupling the technique of SECM with a light source, we have examined the surface charge of non-earthed pseudo-DSCs under variable light conditions and screened substrates by varying the working electrode potential. By studying the surface currents in a series of tests in which one or more component of a DSC were varied, the effect of $\mathrm{TiO}_{2}$, dye and iodide/triiodide electrolyte on the surface characteristics have been examined.
\end{abstract}

\section{Introduction}

Scanning electrochemical microscopy (SECM) has recently become a method of great interest and potential for the examination of the surface properties of photoactive systems has recently become an area of interest due to its high sensitivity for observing surface effects at and below the micrometer scale $[1,2]$.

In a feedback SECM experiment, a standard three electrode electrochemical cell is used in the presence of a redox active electrolyte and the potential difference between the electrodes is kept constant via potentiostat control. When an ultramicroelectrode (UME) is used as the working electrode and brought within a few tip radii of a solution submerged substrate, the 
effect of the substrate on the diffusion of electrolyte to the UME can be directly monitored. If the substrate is conducting, the rate of electrolyte regeneration will increase, leading to a higher tip current, whereas an insulating or electrochemically inactive substrate at micrometer distances will block the diffusion of redox species to the microelectrode, leading to a concurrent decrease in tip current (Fig. 1). Upon the application of a constant potential, changes in the tip current arising from the nature of the substrate can be observed while the UME scans the substrate surface [1].
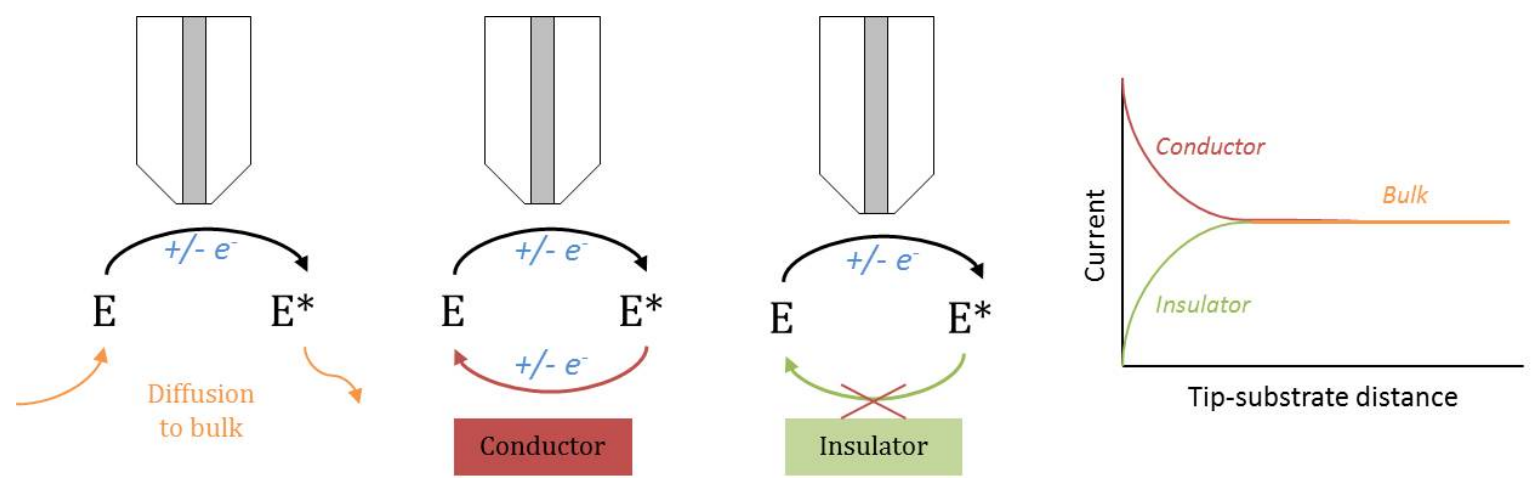

Fig. 1: Working principle and schematic current profiles for SECM experiments showing the enhanced and reduced current detected by the UME above conducting and insulating substrate regions compared to the bulk signal.

SECM has been previously used to investigate the effects of illumination on the surface properties of a number of photochemically active species $[3,4]$ and kinetic and structural investigations of surfaces in catalytic or reactive systems have been reported $[5,6]$. One of us reported the use of the SECM for studying charge carrier effects resulting from a light pulse on a DSC [7]. In this present paper, we discuss further developments on these systems together with investigations into optimizing the SECM to allow for testing of dyes for DSC applications.

In a standard DSC, a photoactive dye is adsorbed to a nanoparticulate titanium dioxide (anatase) layer between two electrodes (typically FTO covered glass) and a redox-active 
electrolyte is added to the cell to enable dye regeneration (Fig. 2(a)). A number of electrochemical and photo-electrochemical processes take place within a DSC cell [8]. After irradiation, the excited dye injects an electron into the $\mathrm{TiO}_{2}$ layer, resulting in the formation of an oxidized dye molecule. The injected electron then travels through the $\mathrm{TiO}_{2}$ to the FTO anode from which it moves through the circuit load. Meanwhile, the dye is returned to its reduced state by electron transfer from the electrolyte and the concomitant formation of an oxidized electrolyte species. Oxidized electrolyte ions migrate to the platinum coated FTO cathode where they are reduced. In addition, undesirable back reactions, such as recombination of anodic electrons and active electrolyte, are possible and reduce the efficiency of the DSC. In an attempt to minimize these interactions, a number of electrolytic systems have been developed of which the iodide/triiodide $\left(\mathrm{I}^{-} / \mathrm{I}_{3}^{-}\right)$couple is the most common [9].

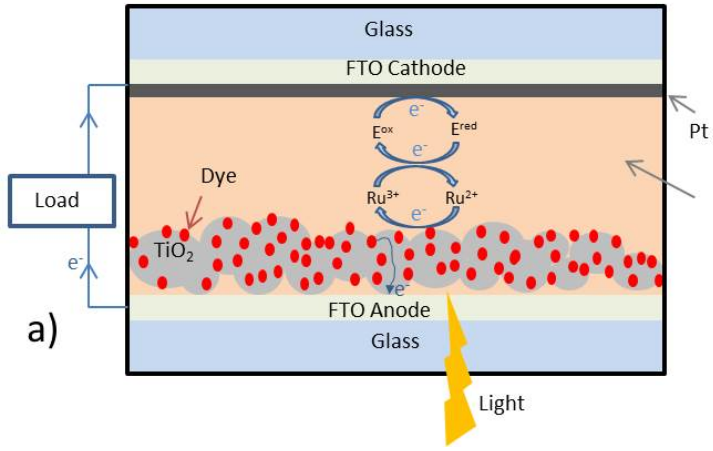

Fig. 2: Diagrammatic representations of (a) the DSC and (b) the SECM-DSC cell configuration

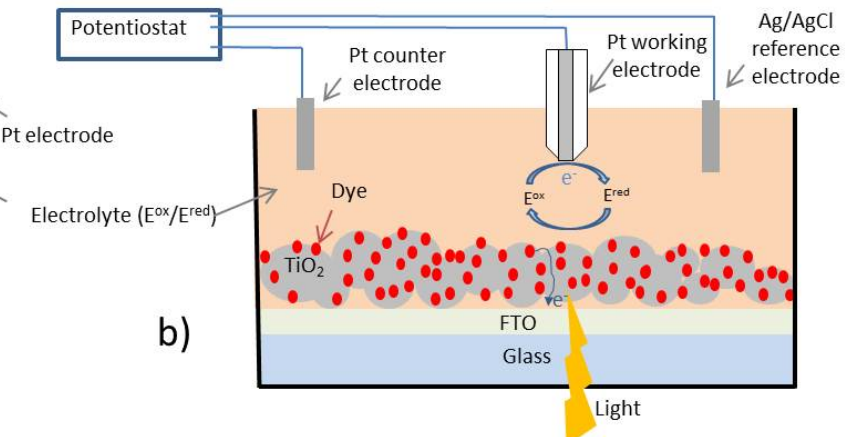

Systematic studies of DSCs using SECM techniques have shown that changes in the electrode configuration, electrolyte composition or dye counter ion can significantly affect the signalto-noise ratio observed in the surface response [10]. SECM techniques have been used to model a DSC cell through earthing or biasing the FTO anode and examining the electron injection from the dye-coated $\mathrm{TiO}_{2}$ to the anode upon excitation of the dye [10,11]. Although 
such investigations give valuable information about the cell, their dependence upon the electron injection pathway does not readily permit systematic studies of the effect of changing the dyes. In contrast, we have removed the electron sink by maintaining the $\mathrm{FTO} / \mathrm{TiO}_{2} / \mathrm{dye}$ as an unearthed substrate and measured the build-up of charge on the surface as the dye is excited by an external light source. This SECM-based setup allows for the investigation of a single interfacial region (between the substrate and $\mathrm{I}^{-} / \mathrm{I}_{3}{ }^{-}$couple) within the pseudo-DSC allowing for the systematic variation of cell components within this region. Changing the dye leads to variations in the observed current at the working UME resulting from both electron injection into the titanium dioxide layer and regeneration of states under pseudo-DSC conditions. SECM methods allow for changes in these properties as the substrate and electrolyte are varied to be studied in a unique way, as well as permitting the examination of average charge for relatively large surface. As a proof of concept towards this end, initial cell configurations were examined using $\mathrm{I}^{-} / \mathrm{I}_{3}{ }^{-}$as the redox electrolyte and two commercially available ruthenium dyes N719 and N749 as the photoactive species.

Cyclic voltammetry studies (Pt pseudo-reference) upon the $\mathrm{I}^{-} / \mathrm{I}_{3}^{-}$electrolyte show that it undergoes a reduction at $\mathrm{E}_{1 / 2}-0.3 \mathrm{~V}$ for the reaction $\mathrm{I}_{3}{ }^{-}+2 \mathrm{e}^{-} \rightarrow 3 \mathrm{I}^{-}$and an oxidation attributed to the reaction $\mathrm{I}_{3}^{-} \rightarrow 1.5 \mathrm{I}_{2}+\mathrm{e}^{-}$at $\mathrm{E}_{1 / 2}+0.25 \mathrm{~V}$ [12]. At lower concentrations of electrolyte the reduction below $-0.3 \mathrm{~V}$ becomes irreversible further limiting the SECM potential window. The available potentials are relatively close, and we decided to examine the redox effects of the surface upon the UME under bias within the potential window of -0.25 to $+0.25 \mathrm{~V}$ in which our diluted system shows redox stability. This allows for the application of a potential within the optimal range of the electrolyte along with minimising unwanted back reactions at the counter electrode of the SECM; it also leads to sufficient current in the bulk electrolyte remote from the surface. In our setup, illumination of the dye results in the generation of both electrons and holes at the surface. The effect of these surface charges can be observed via 
changes in the diffusion layer of electrolyte towards the biased UME within micrometer distances of the substrate surface. By using this system, we can examine variations in the surface charge upon irradiation when either the dye or electrolyte is changed. This allows for the systematic comparison of different dyes under the same electrolytic conditions and vice versa.

\section{Experimental section}

\subsection{Substrate preparation}

$\mathrm{TiO}_{2}$ paste was prepared adapting the procedure of Grätzel and co-workers [13]; changes to the published procedure were the use of a porcelain (in place of alumina) mortar, sonicator bath in place of an ultrasonic horn, terpineol (CAS: 8000-41-7) rather than $\alpha$-terpineol, and the omission of the three roller mill treatment. The FTO glass (Solaronix TCO22-7, $2.2 \mathrm{~mm}$ thickness, sheet resistance $\approx 7 \Omega$ square $^{-1}$ ) was cleaned by sonicating in acetone, EtOH, Hellmanex ${ }^{\circledR}$ surfactant ( $2 \%$ in water), water and $\mathrm{EtOH}$ baths sequentially for $10 \mathrm{~min}$. After treatment in a UV-O $\mathrm{O}_{3}$ system (Model 256-220, Jelight Company Inc.), the FTO plates were immersed in aqueous $\mathrm{TiCl}_{4}$ solution $(40 \mathrm{mM})$ at $70{ }^{\circ} \mathrm{C}$ for $30 \mathrm{~min}$, and washed with $\mathrm{H}_{2} \mathrm{O}$ and EtOH. FTO/TiO 2 substrates were made by doctor blading $\mathrm{TiO}_{2}$ paste [14] onto a conducting glass slide and kept at room temperature for $10 \mathrm{~min}$ to allow the paste to mature in order to minimize surface irregularities. The substrate was then gradually heated under an air flow at $70{ }^{\circ} \mathrm{C}$ for $30 \mathrm{~min}, 135^{\circ} \mathrm{C}$ for $5 \mathrm{~min}, 325^{\circ} \mathrm{C}$ for $5 \mathrm{~min}, 375^{\circ} \mathrm{C}$ for $5 \mathrm{~min}, 450{ }^{\circ} \mathrm{C}$ for $15 \mathrm{~min}$, and $500{ }^{\circ} \mathrm{C}$ for $15 \mathrm{~min}$. After annealing, the $\mathrm{TiO}_{2}$ film was treated with $40 \mathrm{mM} \mathrm{TiCl}_{4}$ solution as described above, rinsed with $\mathrm{H}_{2} \mathrm{O}$ and $\mathrm{EtOH}$ and sintered at $500{ }^{\circ} \mathrm{C}$ for $30 \mathrm{~min}$. After cooling to $\approx 80{ }^{\circ} \mathrm{C}$, substrates were immersed in an ethanol solution of dye $(0.3 \mathrm{mM})$ for $24 \mathrm{~h}$ to prepare $\mathrm{FTO} / \mathrm{TiO}_{2} /$ dye substrate. The coloured slides were removed from the solution, washed with $\mathrm{EtOH}$, and dried under an inert gas flow. 


\section{$\underline{2.2 \text { Cell illumination setup }}$}

In order to deliver light effectively over a small area of the surface of the substrate, a modified SECM cell in which a controlled light source irradiates part of the dye functionalized surface has been constructed (Supplemental S1 and S2). A commercially available Thorlabs OSL1EC halogen lamp source was coupled to Thorlabs BFH48-1000 optical wiring $(\varnothing 1000 \mu \mathrm{m}$ core) using an SMA adaptor. This was then placed through a $1.1 \mathrm{~mm}$ diameter hole in the bottom of the SECM cell and a circular piece of Laseroptik UV-FS glass (refractive index $\mathrm{Na}$ $=0.48)$ of thickness $6.35 \mathrm{~mm}$ placed above it in a custom made Teflon base which fitted into a standard SECM $\mu$-holder. The glass has a cut off range $(200-2100 \mathrm{~nm})$ allowing only for light between these wavelengths to affect the substrate surface. Lateral high resolution SECM scans of a test substrate under illumination shows a conical area of diameter $4 \mathrm{~mm}$ affected by the application of light. This is consistent with the area in which light is expected to be observed based upon the wire core, glass size and refractive index (calculated as $4.2 \mathrm{~mm}$ ); its conical shape comes from the experimental setup in which light intensity is greater directly over the position of application and then decreases moving away from the centre. Calibration at different light intensities was carried out using a Thorlabs PM100 power meter fitted with a Thorlabs model D3MM detector head, to measure the total light hitting the surface. From this the light intensity (per $\mathrm{cm}^{2}$ ) was calculated and calibrated relative to the amount of light emitted from the source lamp at different variable settings.

\subsection{Electrolyte preparation}


$\mathrm{I}^{-} / \mathrm{I}_{3}{ }^{-}:$LiI $(25 \mathrm{mM}), \mathrm{I}_{2}(2.5 \mathrm{mM})$, 1-methylbenzimadiazole $(25 \mathrm{mM})$ and 1-butyl-3methylimidazolium iodide $(30 \mathrm{mM})$ in 3-methoxyproponitrile [15]. (Values have been diluted by a factor of 20 from literature to optimize resolution in the SECM).

\subsection{Electrochemical experiments}

All scanning electrochemistry microscopy (SECM) was performed with a Uniscan $15 \mu \mathrm{m} \mathrm{Pt}$ ultramicroelectrode (UME) close to the substrate surface, using a Uniscan M370 scanning electrochemical microscope operating in feedback mode. The experiments were performed over bare FTO, FTO with a $\mathrm{TiO}_{2}$ layer or ruthenium dye sensitized $\mathrm{TiO}_{2}$ on FTO. UME tips were acid cycled [16], polished and checked under an optical microscope before use. Before the SECM measurements, the substrate surface was levelled using a Wyler high precision (type 72) circular spirit level and checked by measuring line scans for tilt in both the $\mathrm{X}$ and $\mathrm{Y}$ directions. Approach curves were run at appropriate potentials, using the desired electrolyte, in small increments ( $2 \mu \mathrm{m}$ every 5 seconds) in the dark, until the current reached $50 \%$ of the bulk current. For the surface examination, a three electrode setup consisting of a Pt UME working, Pt counter and printed $\mathrm{Ag} / \mathrm{AgCl}$ reference electrodes were employed (Fig. 2(b)).

Square wave voltammograms were recorded on a $\mathrm{CH}$ Instruments $900 \mathrm{~B}$ potentiostat using a solid $\mathrm{FTO} / \mathrm{TiO}_{2} /$ dye substrate prepared as described above as the working electrode. These were submerged in a 3-methoxyproponitrile solution containing $0.1 \mathrm{~mol} \mathrm{dm}^{-3}\left[{ }^{\mathrm{n}} \mathrm{Bu}_{4} \mathrm{~N}\right]\left[\mathrm{PF}_{6}\right]$ as supporting electrolyte and a three electrode setup established using platinum mesh and printed $\mathrm{Ag} / \mathrm{AgCl}$ as the counter and reference electrodes respectively. All solutions were degassed with argon before examination and run in the dark. Scans were run in the negative direction from $\mathrm{E}_{\mathrm{i}}=0 \mathrm{~V}$ to $\mathrm{E}_{\mathrm{f}}=-1.0 \mathrm{~V}, \mathrm{E}_{\mathrm{sw}}=25 \mathrm{mV}, \mathrm{f}=15 \mathrm{~Hz}$, and $\Delta \mathrm{E},=4 \mathrm{mV}$.

\section{Results and Discussion}


In order to test the SECM setup for examination of dyes under illumination it was decided first to optimize the setup using $\mathrm{N} 719$ dye and the standard $\mathrm{I}^{-} / \mathrm{I}_{3}{ }^{-}$electrolyte. Initial investigations showed that the electrolyte itself has a response to irradiation resulting in an increase in the bulk current which rendered examination of the surface effects difficult. The electrolyte was examined in a series of dilution experiments to optimize the concentrations for examination of dyes. These studies showed that dilution of $\mathrm{I}^{-} / \mathrm{I}_{3}{ }^{-}$electrolyte by a factor of 20 relative to literature concentrations gave optimum resolution (See $\mathrm{S} 3$ ). The $\mathrm{FTO} / \mathrm{TiO}_{2} / \mathrm{N} 719$ substrates were irradiated $\left(50 \mathrm{~mW} \mathrm{~cm}{ }^{-2}\right.$ intensity) from underneath and a $6 \times 6 \mathrm{~mm}^{2}$ area of the surface scanned at intervals of $33.3 \mu \mathrm{m}$. The voltages applied between the working and counter electrodes were within the range -0.25 to $+0.25 \mathrm{~V}$ (versus $\mathrm{Ag} / \mathrm{AgCl}$ ) in which minimal redox processes occur at the working electrode. The system was calibrated using standard SECM approach techniques [1] and the tip held at a distance of $30 \mu \mathrm{m}$ from the surface.

When a positive potential $(+0.25 \mathrm{~V})$ is applied to the working electrode, no significant current variations arising from the illuminated dye can be observed. However a small increase in overall current compared to a non-illuminated substrate can be seen (Fig. 3) and some surface topology is resolved. In this setup, a circular $\mathrm{TiO}_{2}$ layer of thickness $10-12 \mu \mathrm{m}$ and diameter 5 mm with N719 is placed upon a FTO plate. As the tip is held at a constant height, an increased current is seen when the UME tip is over the FTO (darker area in Fig. 3) compared to $\mathrm{TiO}_{2}$ (brighter area in Fig. 3) due to the larger distance between the UME and the substrate surface. As the current background of these samples is relatively large (100 nA range) it is unlikely that any localized light-induced electron density would be observed. 

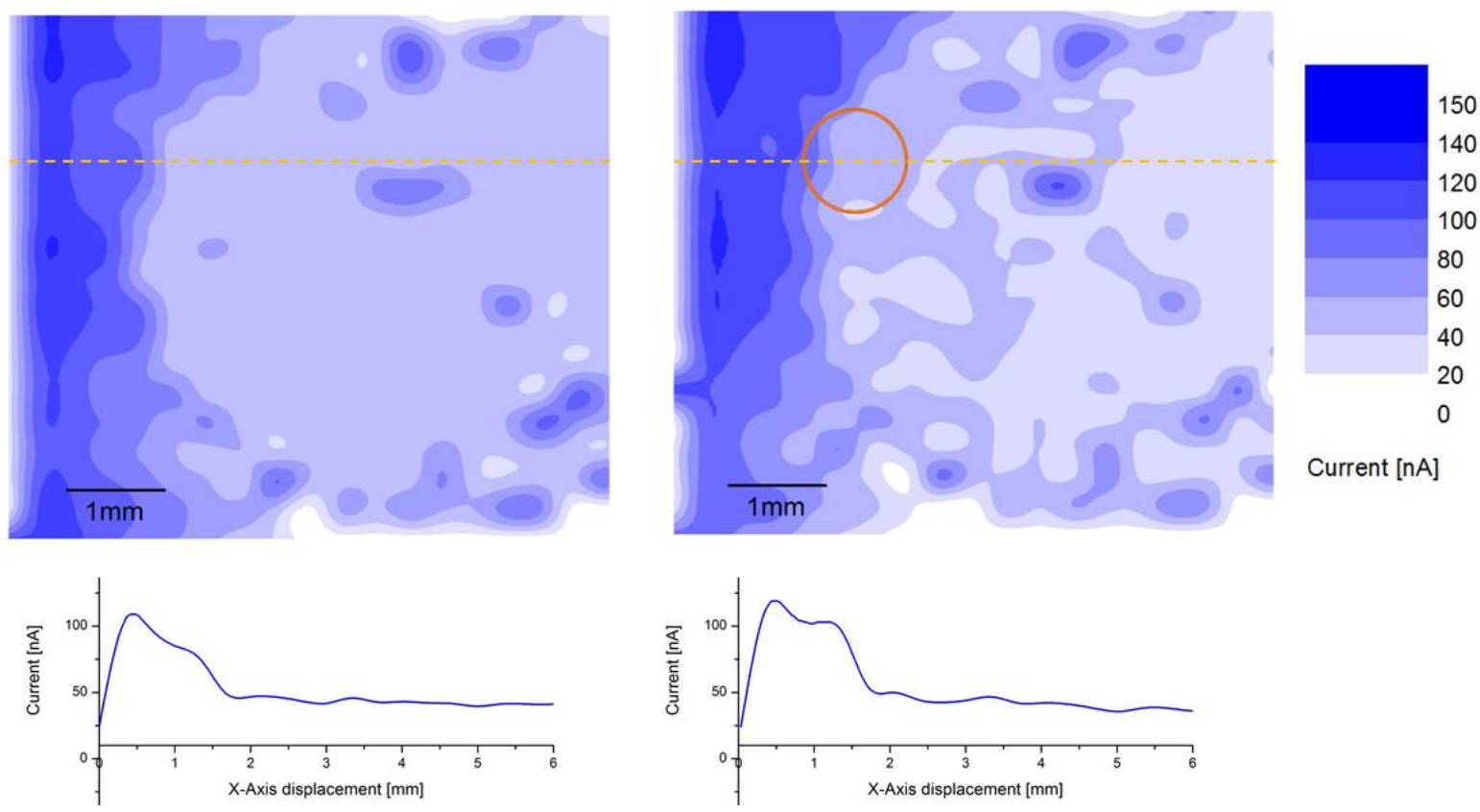

Fig. 3: Area and profile scans of a circular substrate (diameter $5 \mathrm{~mm}$ ) in the dark (left) and

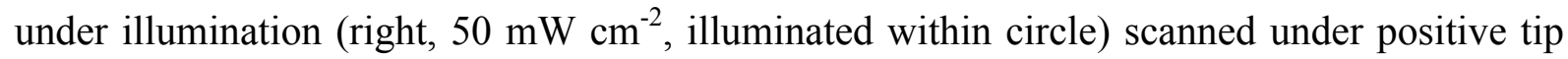
bias $(+0.25 \mathrm{~V})$ using $\mathrm{I}^{-} / \mathrm{I}_{3}^{-}$electrolyte.

In the $\mathrm{I}^{-} / \mathrm{I}_{3}{ }^{-}$redox couple, upon applying a negative potential $(-0.25 \mathrm{~V})$ an increase in current compared to the dark current is observed, centred upon the area irradiated, with a conical current profile (Fig. 4). As the potential applied is kept low in order to prevent irreversible reduction of the electrolyte, the current response is an order of magnitude smaller than that seen when applying positive potentials, where some reversible oxidation can occur. This change can further be seen in the contours of the surface scans where small variations (4-5 nA) due to an inherent tilt in the system can clearly be seen at negative potentials while at positive potentials the higher currents involved make these small variations negligible. 

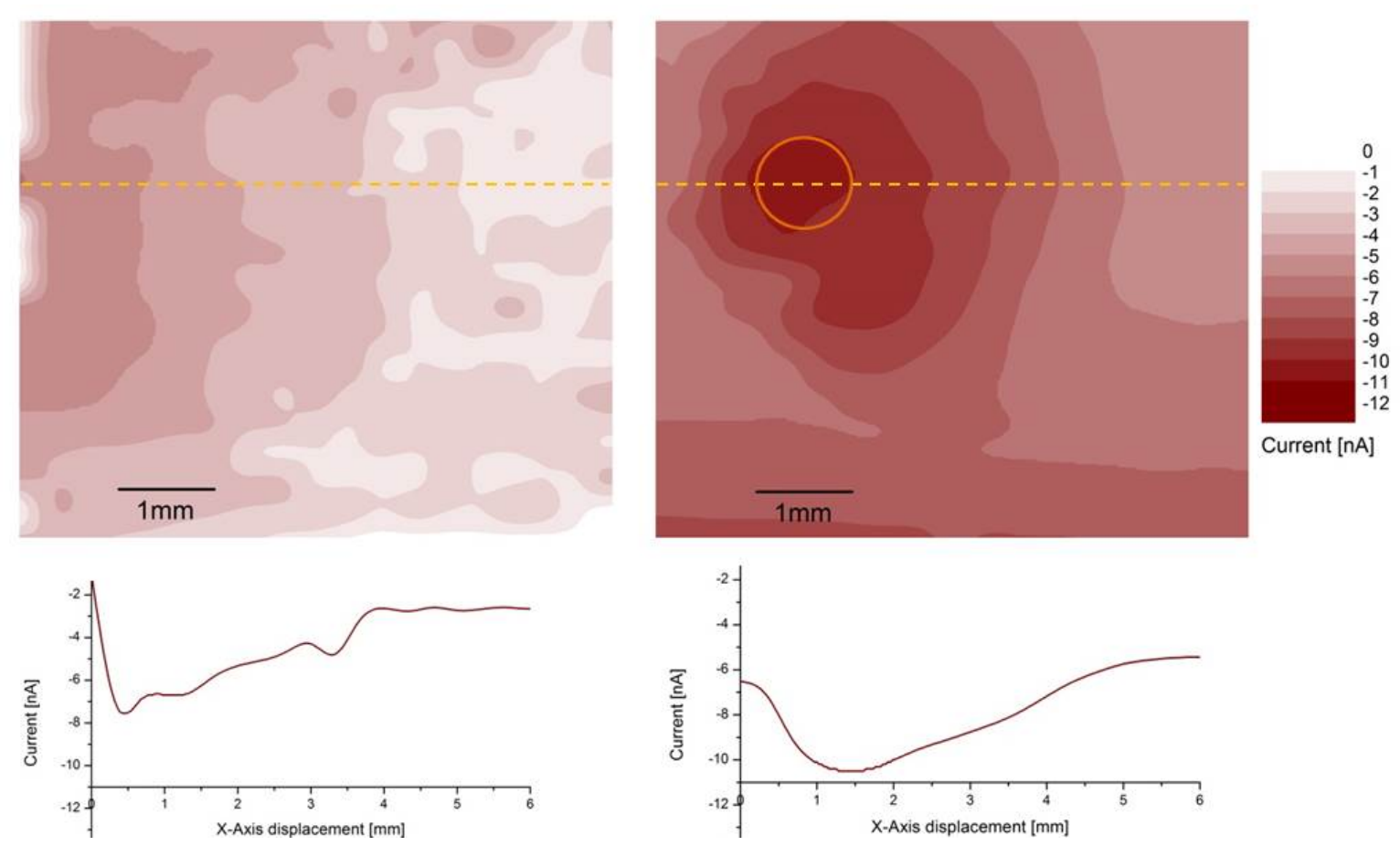

Fig. 4: Area and profile scans of a circular substrate (diameter $5 \mathrm{~mm}$ ) in the dark (left) and

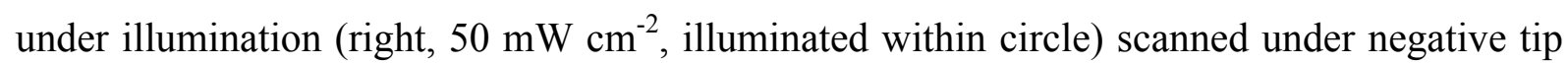
bias $(-0.25 \mathrm{~V})$ using $\mathrm{I}^{-} / \mathrm{I}_{3}^{-}$electrolyte.

The shape of the negative scan curve is due to the experimental setup in which the light can diffuse through the glass under the substrate. It is worth noting that upon irradiation, a shift in the electrolyte background current of up to $1 \mathrm{nA}$ is also seen. It appears that this current response is due to the excitation of the N719 dye on the surface and the transfer of electrons into the titanium dioxide layer. As a consequence, an excess of holes are observed at the substrate surface (Fig. 5). A similar response was also observed for the N749 dye. 


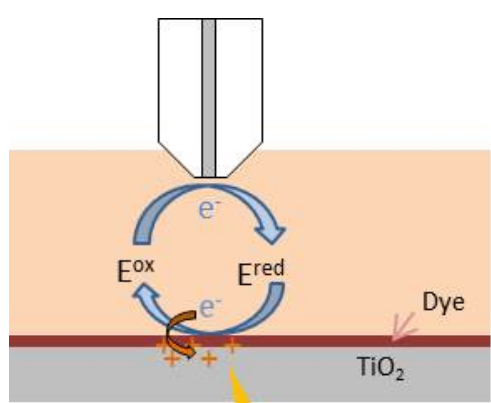

Light

Fig. 5: Increase in current flow due to charge at the surface as light is applied.

For those potentials at which a current well was observed, the increase between the background and well maximum was calculated. Examination of these values as a function of UME potential for both N719 and N749 shows that the magnitude of the current well depends upon the potential used to observe it (Fig. 6).

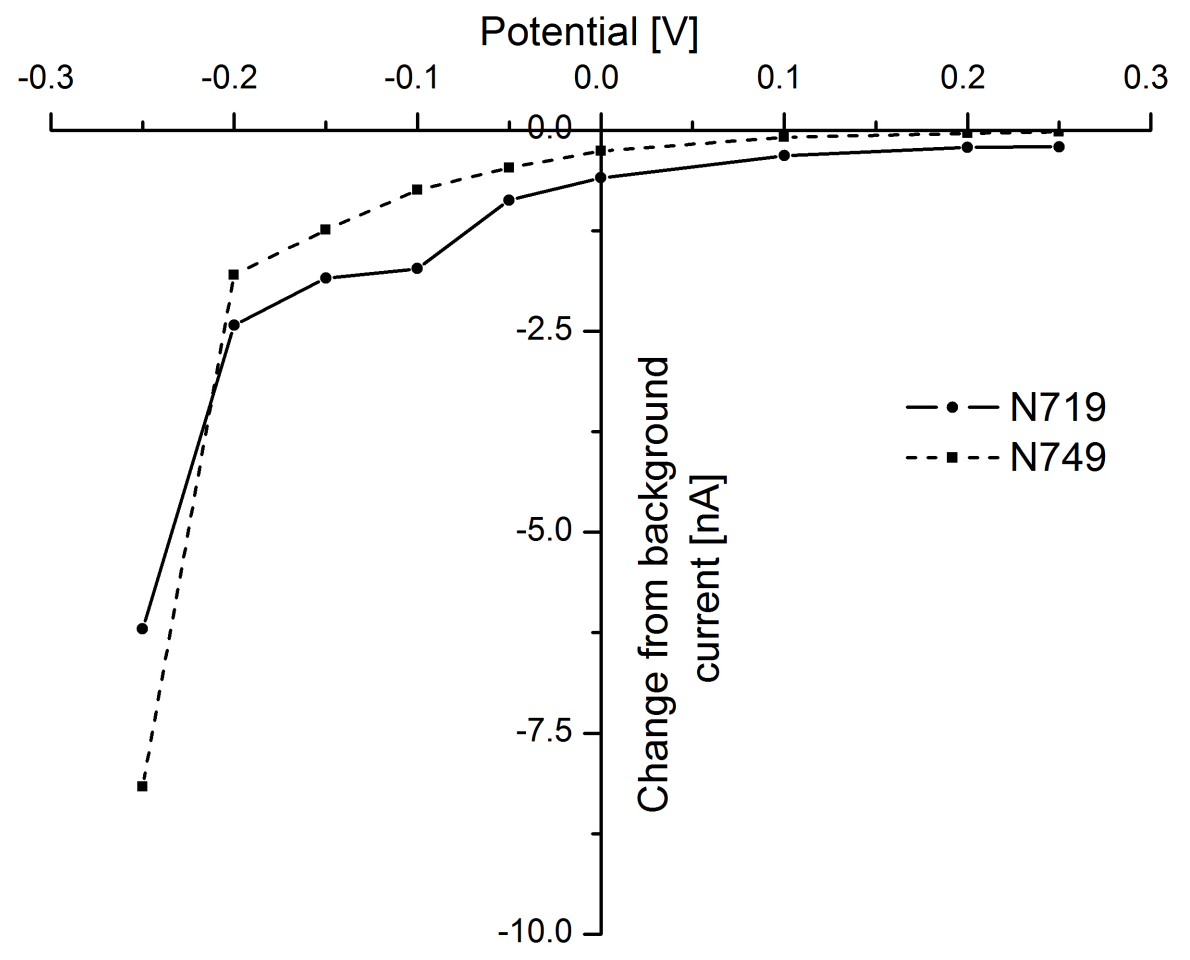

Fig. 6: Maximum current difference as UME potential is varied under illumination $(50 \mathrm{~mW}$ $\mathrm{cm}^{-2}$ ) for N719 (solid line) and N749 (dashed line) substrates. 
In all cases the light applied to the substrate and the electrolyte remain unchanged; as such the changes in response are due to the experimental setup, with a maximum dependent both on the tip potential and the amount of dye adsorbed on the surface. For both dyes there is a gradual increase in well depth as the applied potential is decreased as far as $-0.2 \mathrm{~V}$. Beyond $0.2 \mathrm{~V}$ the observed current rises by approximately a factor of three as a result of increasing interactions between surface charges and the diffusion layer around the UME. Comparison of the response from the SECM with those observed in square wave electrochemical analysis of a $\mathrm{FTO} / \mathrm{TiO}_{2} /$ dye substrate scanned from 0.0 to $-1.0 \mathrm{~V}$ (Fig. 7) shows that this current increase comes within the same potential region where reduction of the adsorbed dye begins.

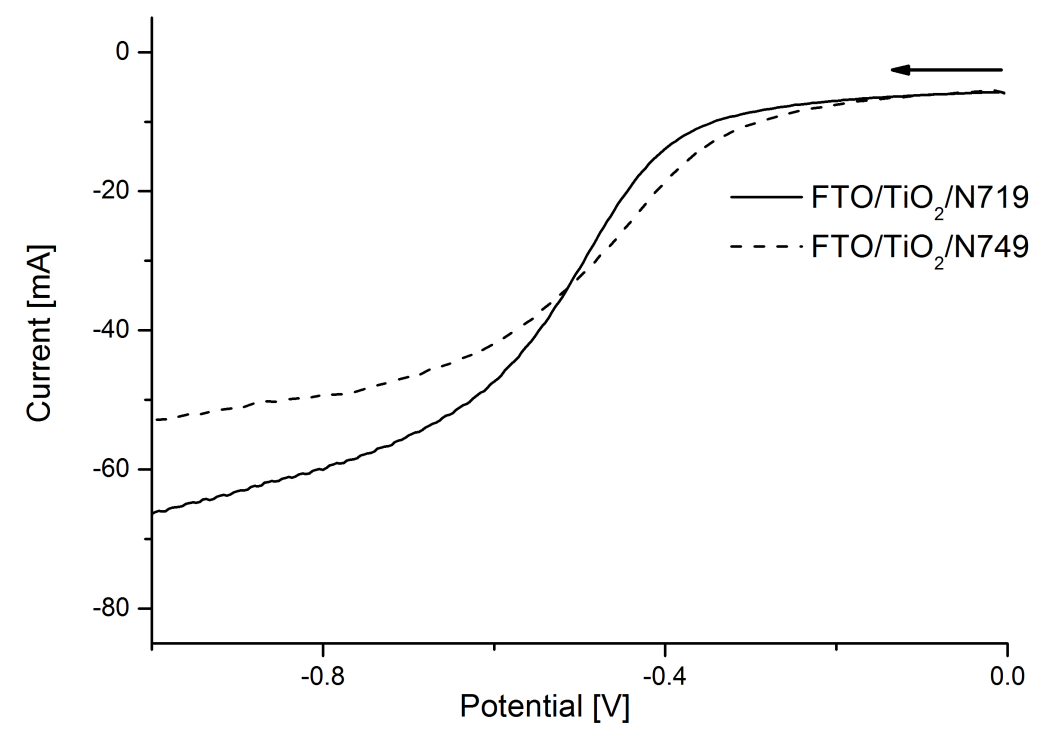

Fig. 7: Square wave voltammograms $(-0.0$ to $-1.0 \mathrm{~V})$ for $\mathrm{TiO}_{2}$ on FTO with adsorbed N719 and N749 dyes.

If the SECM setup is operating as a pseudo-DSC it can be assumed that the increase in current at negative applied potential directly influences the local electron density. This may be correlated to the local recombination dynamics for different dye sensitized layers; however more detailed experiments are necessary. 
For our SECM-DSC setup there are two factors controlling where the cell can be tested, the potential at which the electrolyte is irreversibly reduced and the potential in which the dye response is greatest. For both N719 and N749 the optimal UME potential is $-0.25 \mathrm{~V}$; however for other dyes this value may differ. Indeed it is worth noting that this reductive dye limit depends upon the inherent nature of the dye and is independent of other substrate components.

In order to confirm that the increase in current upon illumination was an effect both of the excitation of the dye and of the interactions between the dye and the $\mathrm{I}^{-} / \mathrm{I}_{3}{ }^{-}$electrolyte, a series of control experiments were carried out in which one or more of the components of a N719 DSC substrate were varied or removed (Table 1).

Table 1: Current response for different DSC configurations, UME always $30 \mu \mathrm{m}$ from the surface, irradiation $50 \mathrm{~mW} \mathrm{~cm} \mathrm{c}^{-2}$, all scans run at $-0.25 \mathrm{~V}$ bias.

\begin{tabular}{cccc}
\hline $\begin{array}{c}\text { Substrate } \\
\text { components }\end{array}$ & Electrolyte & $\begin{array}{c}\text { Max current observed } \\
\text { under illumination }\end{array}$ & $\begin{array}{c}\text { Current change } \\
\text { upon illumination }\end{array}$ \\
\hline $\mathrm{Bare} \mathrm{FTO}$ & $\mathrm{I}^{-} / \mathrm{I}_{3}^{-}$ & $-5.0 \mathrm{nA}$ & $0.0 \mathrm{nA}$ \\
$\mathrm{FTO} / \mathrm{TiO}_{2}$ & $\mathrm{I}^{-} / \mathrm{I}_{3}^{-}$ & $-6.2 \mathrm{nA}$ & $1.2 \mathrm{nA}$ \\
$\mathrm{FTO} / \mathrm{TiO}_{2} / \mathrm{N} 719$ & $\mathrm{I}^{-} / \mathrm{I}_{3}^{-}$ & $-11.2 \mathrm{nA}$ & $6.2 \mathrm{nA}$
\end{tabular}

For bare $\mathrm{TiO}_{2}$ an increase in current from $-5.0 \mathrm{nA}$ to a maximum of $-6.2 \mathrm{nA}$ is observed upon irradiation. This small increase can be attributed to photo-induced changes in the band gap of the semiconductor which result in minor variations in the conductance properties of the titanium dioxide surface. Resulting from this is a small increase in current flow observed when the UME passes over the surface of the substrate. This enhancement in surface current is increased in the presence of N719, with a maximum current of $-11.2 \mathrm{nA}$ being observed. For examining a library of dyes for DSCs using SECM, it is important to use the same electrolyte for each to allow valid comparisons to be made. From existing DSC studies and our initial optimization experiments it appears that the $\mathrm{I}^{-} / \mathrm{I}_{3}^{-}$electrolyte couple is, upon 
dilution, the most suitable for SECM-DSC dye experiments. This in turn validates the use of the SECM setup as a method to screen dyes and electrolytes.

Once the optimum configurations for the two dyes in a SECM-pseudo-DSC setup had been established, we decided to investigate the changes in substrate response as light is turned on and off under constant applied potential. In order to do this, the tip was placed within $30 \mu \mathrm{m}$ of the substrate surface and the system was allowed to equilibrate for 12 minutes at $-0.25 \mathrm{~V}$. The current at the UME was then measured under constant potential as light $\left(70 \mathrm{~mW} \mathrm{~cm}^{-2}\right)$ was applied for 30 min and then switched off. The changes upon variable light application were recorded in order to gain information regarding charge formation and dissipation from the excited substrate.
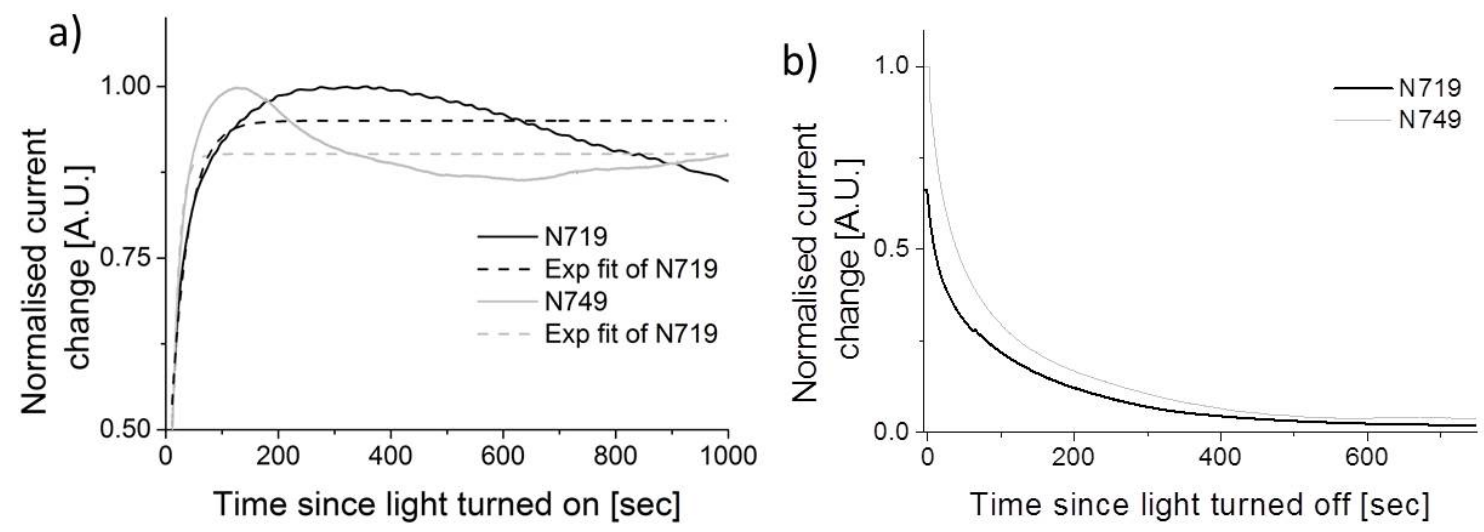

Fig. 8: Changes in current at the surface of N719 (black line) and N749 (grey line) substrates as light is turned (a) on and (b) off (irradiation $70 \mathrm{~mW} \mathrm{~cm}^{-2}$, scans run at $-0.25 \mathrm{~V}$ bias).

In order to correct for the variations in current response resulting from the different concentrations of each dye adsorbed on the titanium dioxide layer the plots were normalized relative to the current maximum in each case. For both dyes an increase in current at the UME is observed upon light application. This process appears to have two main components; firstly 
a slow part related to long term degradation processes as the cell is illuminated. The second, faster component (Fig. 8 (a, dashed lines)) shows clear exponential behaviour, with lifetimes between 15 and 20 seconds and can be related to charge diffusion processes. After illumination charge begins to evolve at the titanium dioxide surface as a result of electron injection from the dye; in order to balance this a local equilibrium is reached between the charged surface and the electrolyte. This process appears to vary depending on the dye present at the surface with faster equilibrium achieved in the case of N749. For N719 this maximum begins to decay, with a fall of $30 \%$ within 30 minutes, as a result of long term degradation. When light is removed, both dyes return to their ground state with a comparable loss of charge on the surface with time as a consequence of recombination of the charge on the surface with the electrolyte. For both substrates this decay occurs in a similar timeframe with relaxation complete within 500 seconds (Fig. 8b).

\section{Conclusion}

Initial investigations into the use of scanning electrochemical microscopy as a tool for examining cell components for DSC applications are reported. By studying a non-earthed substrate, positive charge build up on the surface of a pseudo-DSC has been observed with negative UME tip potentials. Using the commercial N719 dye, a five-fold increase in the current at the surface upon irradiation compared to bare $\mathrm{TiO}_{2}$ has been observed. In addition, an initial kinetic study showing charge responses at the surface as light is applied and removed has been carried out for N719 and N749.

This optimized SECM methodology shows great potential for the screening of dyes, electrolytes and semiconductor combinations for DSC applications. By examination of the surface currents for ruthenium dyes we have optimized the system to permit studies of other 
candidate dyes in a pseudo-DSC environment. This will provide valuable insight into relationships between the properties of dyes and overall cell performance.

\section{Acknowledgements}

We thank the European Research Council (Advanced Grant 267816 LiLo), the Swiss National Science Foundation, the Nano Argovia programme of the Swiss Nanonscience Institute and the University of Basel for financial support. Sebastian Fürer is thanked for input on electrolyte compositions.

\section{References}

[1] A.J. Bard, F.R.F. Fan, J. Kwak, O. Lev, Scanning electrochemical microscopy. 1. Introduction and principles. Anal. Chem. 61 (1989) 132.

[2] S. Amemiya, A.J. Bard, F.R.F. Fan, M.V. Mirkin, P.R. Unwin, Scanning Electrochemical Microscopy, Annu. Rev. Anal. Chem. 1 (2008) 95.

[3] Y. Shen, U.M. Tefashe, K. Nonomura, T. Loewenstein, D, Schlettwein. G. Wittstock, Photoelectrochemical kinetics of eosin Y-sensitized zinc oxide films investigated by scanning electrochemical microscopy under illumination with different LED, Electrochim. Acta 55 (2009) 458.

[4] U.M. Tefashe, T. Loewenstein, H. Miura, D, Schlettwein, G. Wittstock, Scanning electrochemical microscope studies of dye regeneration in indoline (D149)-sensitized ZnO photoelectrochemical cells, J. Electroanal. Chem. 650 (2010) 24.

[5] J.L. Fernández, D. A. Walsh, A.J. Bard, Thermodynamic Guidelines for the Design of Bimetallic Catalysts for Oxygen Electroreduction and Rapid Screening by Scanning Electrochemical Microscopy. M-Co (M: Pd, Ag, Au), J. Am. Chem. Soc. 127 (2005) 357.

[6] A. Barker, P. Unwin, J. Zhang, Measurement of the forward and back rate constants for electron transfer at the interface between two immiscible electrolyte solutions using scanning electrochemical microscopy (SECM): Theory and experiment, Electrochem. Commun. 3 (2011) 372 .

[7] B. Bozic, E. Figgemeier, Scanning electrochemical microscopy under illumination: an elegant tool to directly determine the mobility of charge carriers within dye-sensitized nano structured semiconductors, Chem. Commun. (2006) 2268.

[8] B. Li, L. Wang, B. Kang, P. Wang, Y. Qiu, Review of recent progress in solid-state dyesensitized solar cells, Sol. Energ. Mat. Sol. Cells 90 (2006) 549.

[9] G. Boschloo, A. Hagfeldt, Characteristics of the iodide/triiodide redox mediator in dyesensitized solar cells, Acc. Chem. Res. 42 (2009) 1819. 
[10] W. Kylberg, A. Wain, F. Castro, Screening of photoactive dyes on TiO2 surfaces using scanning electrochemical microscopy, J. Phys. Chem. C 116 (2012) 17384.

[11] U. Tefashe, K. Nonomura, N. Vlachopoulos, A. Hagfelt, G. Wittstock, Effect of cation on dye regeneration kinetics of $\mathrm{N} 719$-sensitized $\mathrm{TiO}_{2}$ films in acetonitrile-based and ionicliquid-based electrolytes investigated by scanning electrochemical microscopy, J. Phys.

Chem. C 116 (2012) 4316.

[12] Y. Shen, K. Nonomura, D. Schlettwein, C. Zhao, G. Wittstock, Photoelectrochemical kinetics of eosin $\mathrm{Y}$-sensitized zinc oxide films investigated by scanning electrochemical microscopy, Chem. Eur. J. 12 (2006) 5832.

[13] S. Ito, T.N. Murakami, P. Comte, P. Liska, C. Grätzel, M. K. Nazeeruddin, M. Grätzel, Fabrication of thin film dye sensitized solar cells with solar to electric power conversion efficiency over 10\%, Thin Solid Films, 516 (2008) 4613.

[14] B. Bozic-Weber, S.Y. Brauchli, E.C. Constable, S.O. Fürer, C.E. Housecroft, F.J. Malzner, I.A. Wright, J.A. Zampese, Improving the photoresponse of copper(I) dyes in dyesensitized solar cells by tuning ancillary and anchoring ligand modules, Dalton Trans. 42 (2013) 12293.

[15] J. Wu, Z. Lan, S. Hao, P. Li, J. Lin, M. Huang, L Fang, Y. Huang, Progress on the electrolytes for dye-sensitized solar cells, Pure Appl. Chem. 80 (2008) 2241.

[16] K. Fushimi, M. Seo, An SECM observation of dissolution distribution of ferrous or ferric ion from a polycrystalline iron electrode, Electrochim. Acta, 47 (2001) 121. 